\title{
A new species of Apsil Malloch from Chile (Diptera, Muscidae)
}

\section{Márcia Souto Couri ${ }^{1}$}

\author{
ABSTRACT. Apsil diminuta sp. $\mathbf{n}$. is described from Chile. Male terminalia is \\ illustrated. \\ KEY WORDS. Diptera, Muscidae, Apsil, taxonomy, new species, Chile
}

Apsil Malloch, 1929 is a neotropical muscid endemic to South Argentina and Chile. The genus and its nine species were recently revised by COURI (2000). The present new species was found in a material loaned from "Canadian National Collection" (Ottawa, Canada).

\section{Apsil diminuta sp. $\mathbf{n}$.}

Figs $1-12$

Holotype male. CHILE, Osorno: Parque Nac. Puyehue, 20-25-XII-1982, $1180 \mathrm{~m}$. A. Newton \& M. Thayer (CNC). Paratypes with same labels as holotype, 4 males (CNC), 3 males (MNRJ).

Diagnosis. Frons at superior half dark brown, inferior half, parafrontal, face, parafacial and gena faint golden pollinose. Four long pairs of frontal bristles. Gena very high (Fig. 1), acrostichal cilia bisseriated. Claws and pulvili long, specially the ones in fore leg.

Coloration. Frons at superior half dark brown, inferior half; paraf rontal; face, parafacial and gena faint golden pollinose. Vertex and ocellar triangle dark brown. Antena and arista dark brown. Palpus yellow. Mesonotum gray pollinose with brown marks as in figure 2. Pleurae gray pollinose. Calypter white, balancim yellow, apex of capittulum somewhat grey. Wings with very faint brown spots at the end of sub-costal and r-m and dm-cu cross veins. Femora and tibia brown with gray pollinosity, tibia less pollinose, tarsi pale yellow. Abdomen with brown marks as in figure 3.

Length. Male body: 3.5-3.8 mm; wing: 3.0-3.5 mm.

Head. Frons with four long pairs of frontal bristles, intercalated with fine ones, antenna short, flagellomere measuring about 1.6 times the lenght of pedicel; gena very high (Fig. 1); palpus very little dilated at apex (Fig. 4). Proboscis with labellum not reduced and with developed teeth (Fig. 5).

Thorax. Acrostichal hairs in two serics; first pair of pre-sutural dorsocentral bristles about half size of the second onc, the first two post-sutural the same size of the second pre-sutural, and the last the longest. Katepisternal bristles long, the

1) Museu Nacional. Quinta da Boa Vista, São Cristóvāo, 20940-040 Rio de Janeiro, Rio de Janeiro, Brasil. Bolsista Produtividade em Pesquisa, CNPq. 

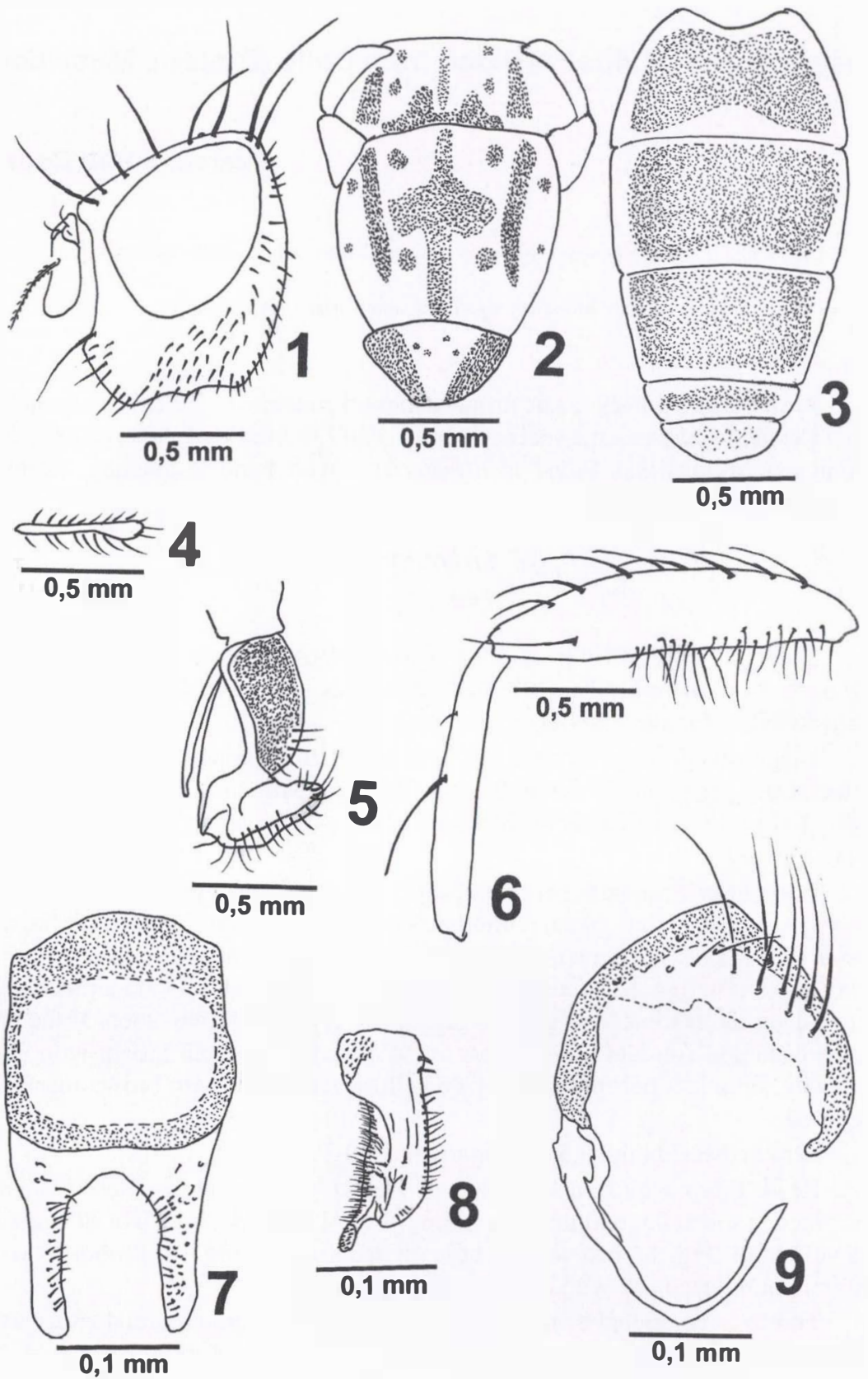

Figs 1-9. Apsil diminuta sp. n., male. (1) Head, lateral view; (2) mesonotum, dorsal view; (3) abdomen, dorsal view; (4) palpi; (5) proboscis; (6) hind femur and hind tibia, lateral view; (7) sternite 5; (8) arm of sternite 5, lateral view; (9) sternite 6. 


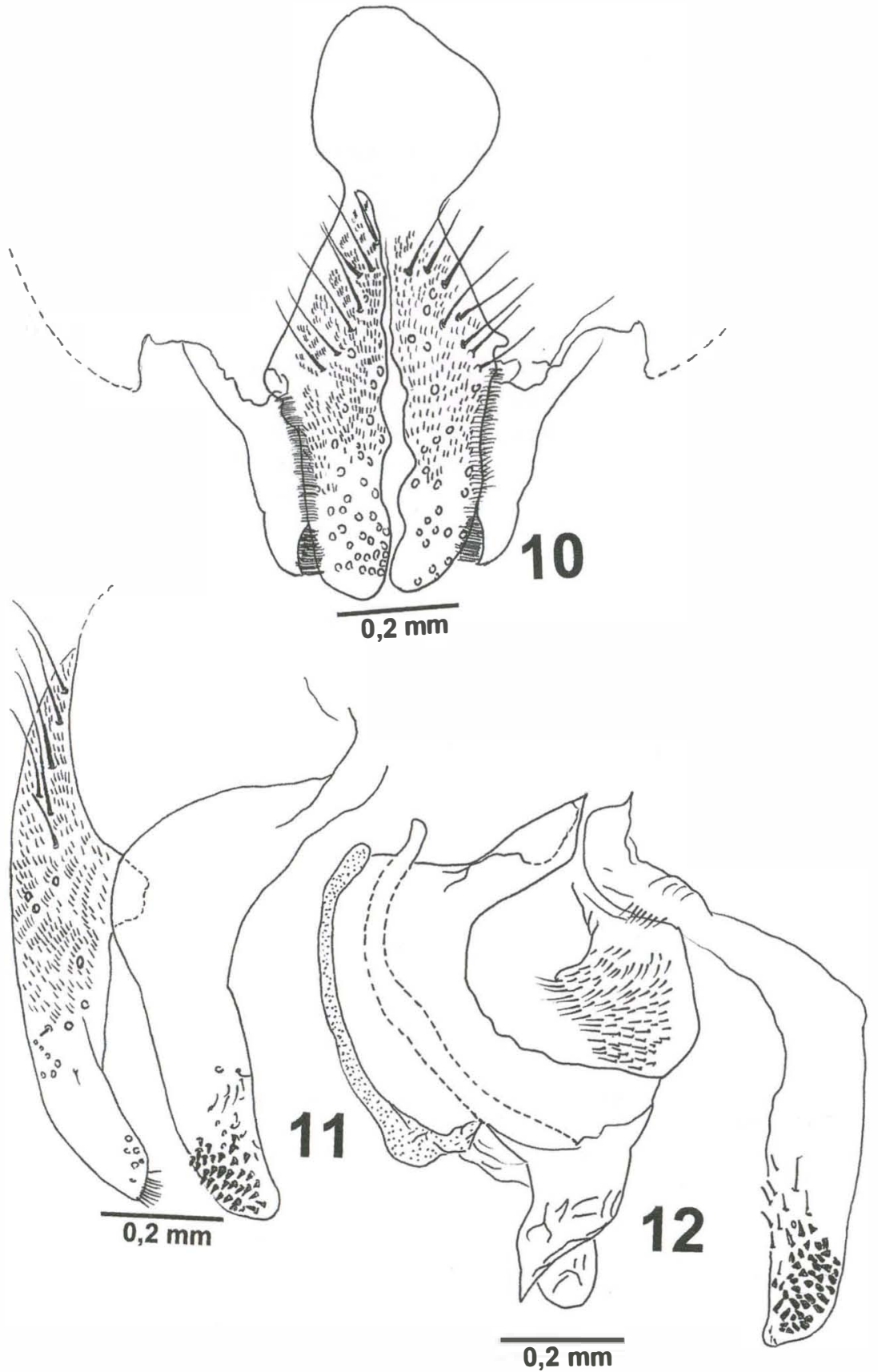

Figs 10-12. Apsil diminuta sp. n., male. (10) Cercal plate and surstili, dorsal view; (11) cercal plate and surstili, lateral view; (12) phallic complex, lateral view. 
posterior longer. Both calypters round, almost the same size, the lower one surpassing the upper only a little. Fore femur on posterodorsal and posteroventral surfaces with a row of bristles. Fore tibia on posterior surface with a median bristle, dorsal pre-apical bristle; posterodorsal and anterodorsal with long and fine pre-apical bristles. Mid femur on ventral surface with 5-7 fine bristles at basal half, posterior surface with two preapical bristles. Mid tibia at posterior surface with a median bristle, anterodorsal surface with a median bristle, dorsal surface with a pre-apical bristle, anterior and ventral surfaces with an apical bristle. Hind femur on anterodorsal surface with a complete row of strong bristles, anteroventral surface with a row of fine bristles, the last one strong; anteroventral, ventral and posteroventral surfaces with many rows of very fine bristles at basal half (Fig. 6). Hind tibia on anterodorsal and posterodorsal surfaces with a long median bristle, dorsal surface with a long pre-apical bristle, anteroventral surface with 2-3 sub-median bristles.

Abdomen. All tergites with marginal row of bristles, the ones in tergite IV, longer; tergite V with a row of discal bristles. Sternite 5 of male with arms "U" shaped (Fig. 7); cilia restricted to arms (Fig. 8); sternite six with a long right arm (Fig. 9).

Terminalia. Male: cercal plate moderately elongate, surstili almost as long cercal plate, with many black short spines on inner apex (Figs 10 and 11); hypandrium tubular (Fig. 12).

Comments. No female in the series. In MaLLOCH (1934) key it could be approximated to $A$. maculiventris, being easily distinguished by the palpi not conspicually dilated at apex, different marks in thorax and abdomen, different bristling at hind femur.

Geographical record. Chile

ACKNOWLEGMENTS. I am grateful to my colleagues at "Canadian National Collection, Ottawa" forthe facilities to study the material. I am also very grateful to the support of "Conselho Nacional de Desenvolvimento Cientifico e Tecnologico", an agency of the Brazilian Government Government fostering scientific and technological development.

\section{REFERENCES}

Couri, M.S. 2000. Revision of Apsil Malloch (Diptera, Muscidae, Coenosiinae, Coenosiini). Studia dipterologica 7 ( I ): 45-57.

Malloch, J.R. 1934. Muscidae. In: Diptera of Patagonia and South Chile. London, Part VII (2), p. 171-346.

Recebido em 01.03.2001; aceito em 30.1.2002.

Revta bras. Zool. 19 (1): $105-108,2002$ 